\title{
MORPHOLOGICAL CHARACTERIZATION OF MALAYSIAN WILD BANANA MUSA ACUMINATA
}

\author{
MUHAMMAD ASIF JAVED*, MAK CHAI and ROFINA YASMIN OTHMAN \\ Division of Genetics \& Molecular Biology, Institute of Biological Sciences, \\ University of Malaya, 50603 Kuala Lumpur, Malaysia
}

\begin{abstract}
Fourteen populations of Musa acuminata ranging from populations in the lowlands of northern (ssp. siamea) to central Malaysian region (ssp. malaccensis) and highland banana (ssp. truncata) were characterized based on chromosome number and 46 morphological characters. A large amount of variation was observed within the populations. However, only highland bananas appeared morphologically distinct. Lowland populations both from northern and central Malaysia were found to be overlapping and no distinguishing pattern was observed. The morphological characters found variable within these populations were related to developmental changes and mutations. The results obtained in this study were not revolutionary. However, the survey of a large number of characters treated with multivariate techniques further sharpened the existing groupings of the Musa acuminata subspecies.
\end{abstract}

Key words: Musaceae/ Malaysia / ssp. malaccensis I ssp. truncata I ssp. siamea

\section{INTRODUCTION}

Banana and plantains are one of the most important tropical fruit crops. They are staple for rural and urban consumers in the humid tropics and an important source of rural income. Bananas are grown in 122 countries of the world with a cultivated area of 3.8 million ha and total production of 56.4 million metric tons both for export and local consumption (FAO 1999).

Banana monoculture cultivation provided a powerful driving force in disease epidemics. It was observed in the case of Gros Michel attacked by Fusarium oxysporum $f$. sp. cubense (FOC) race 1 resulted in the collapse of the banana industry. Gros Michel was then replaced by Cavendish bananas resistant to FOC race 1. However, recent outbreak of a new FOC race 4 attacking Cavendish in subtropics and tropics again threatened the banana industry. There is no chemical control available and the only way is to plant cultivars resistant/tolerant to the pathogen (Buddenhagen 1990).

Malaysia is one of the centers of diversity for both wild and cultivated bananas. Musa acuminata is the most variable species and progenitor of cultivated bananas (Simmonds 1962). M. acuminata was reported to be resistant to Fusarium wilt race 1 (Vakili 1965).

A survey of local wild species has been reviewed by Simmonds (1955) and Kiew (1987) based on morphological characters. Only a few morphological charac- 
ters were used and characters found to be useful for subspecific classification have been further questioned (Hari 1968; Shepherd 1988 and 1999). Therefore, the subspecific grouping of local Musa acuminata has been complicated by taxonomic revisions. Recent renewed emphasis on the utilization of these resources for disease resistant studies for molecular banana breeding elucidated the need to characterize different wild Musa acuminata forms in Malaysia.

For breeding and ease of field identification, taxonomic differentiation based on morphological traits seems to be convenient and useful for evaluating germ-plasm. Hence the present study aims to describe intra-and interspecies variation in different Musa species, using both qualitative and quantitative morphological traits. Multivariate techniques are used to describe relationship and to observe the most variable characteristics.

\section{MATERIALS AND METHOD}

Fourteen populations of wild seeded Musa acuminata species and two of Musa violascens and Musa balbisiana (Fig. 1) were surveyed for this study (Table 1). Suckers collected were all planted on the University Malaya farm under the same environmental conditions to reduce variation due to environmental factors. Suckers were planted in holes to a depth of 30-40 cm with $2 \times 2 \mathrm{~m}$ spacing within and between rows. Weeding was done manually and fertilizer was applied occasionally.

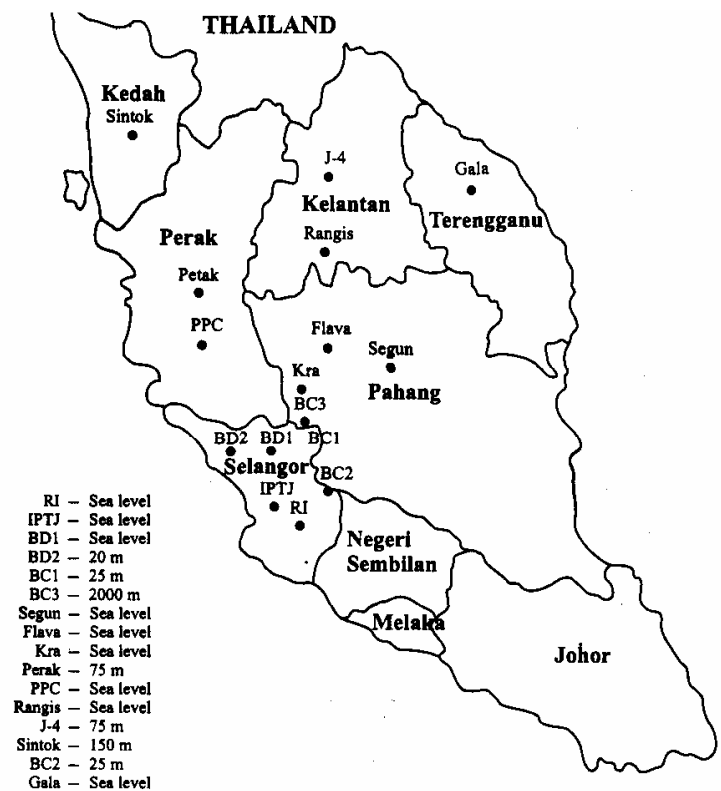

Figure 1. Map showing the locations of sample collections in Peninsular Malaysia. 
Marphological characterization of Malaysian wild banana - Muhammad Asif Javed et al.

Table 1. Wild Musa species samples and their site of collection.

\begin{tabular}{ccccc}
\hline \hline No & Local name /code & Botanical name & *State & Altitude \\
\hline 1 & RI & Musa acuminata & Selangor & Sea level \\
2 & IPTJ & Musa acuminata & Selangor & Sea level \\
3 & BD1 & Musa acuminata & Selangor & Sea level \\
4 & BD2 & Musa acuminata & Selangor & $20 \mathrm{~m}$ \\
5 & BC1 & Musa acuminata & Pahang & $25 \mathrm{~m}$ \\
6 & BC3 & Musa acuminata & Pahang & $2000 \mathrm{~m}$ \\
7 & Segun & Musa acuminata & Pahang & Sea level \\
8 & Flava & Musa acuminata & Pahang & Sea level \\
9 & Kra & Musa acuminata & Pahang & Sea level \\
10 & Perak & Musa acuminata & Perak & $75 \mathrm{~m}$ \\
11 & PPC & Musa acuminata & Perak & Sea level \\
12 & Rangis & Musa acuminata & Kelantan & Sea level \\
13 & J-4 & Musa acuminata & Kelantan & $75 \mathrm{~m}$ \\
14 & Sintok & Musa acuminata & Kedah & 150 \\
15 & BC2 & Musa violascens & Pahang & $25 \mathrm{~m}$ \\
16 & Gala & Musa balbisiana & Terengganu & Sea level \\
\hline
\end{tabular}

*Geographical grouping

Northern Peninsular Malaysia = Kelantan and Kedah Central

Peninsular Malaysia = Pahang, Perak, Selangor Higlands =

Genting and Cameron highlands (Pahang)

A mean number of five specimens were examined for each sample. The data on different morphological characters were taken during first crop cycle. All accessions planted grow well except BC3 (Highland banana) and Musa violascens (BC1) which were dead; therefore, morphological data on these accessions were taken in-situ.

Fruit bunches were also collected for the development of open pollinated seed populations. Initial studies on seed germination in the greenhouse were not successful; therefore, in vitro embryo culture protocol was standardized (Asif et al. 200la).

Ploidy was determined using flow cytometery (FCM) as previously described (Asif et al. 2001). All samples used are diploid where Musa acumlnata and $M$. balbisiana have $(2 \mathrm{n}=22)$ and $M$. violascens $(2 \mathrm{n}=20)$ chromosome number as suggested by Simmonds (1962). The vegetative characters were scored on plants with emerged inflorescence. During this time, maximum development of vegetative parts has taken place (Purseglove 1972). Forty-six characters were used including those suggested by Simmonds (1955) and IPGRI descriptors (1996). Thirty-five qualitative and 11 quantitative characters were included. Simple two-state qualitative characters ordered multi-state characters were coded as series of discrete states (Table 2). Characters related to color were examined using a standard color chart (IPGRI 1996). Mean values for continuous quantitative characters for the minimum five randomly selected healthy plants per accession were calculated.

Phonetic analyses were carried out using SPSS-PC FOR WINDOWS version 9.0 (Norusis 1985). Cluster analysis and principal component analysis were carried 
out on a data set including both metric and binary data. A distance matrix of Squared Euclidean Distance was calculated. This distance was used as a measure of phenetic difference. Clustering was carried out by single linkage method.

Table 2. Description of morphological characteristics based on banana descriptor (IPGRI 1996) and Simmonds (1955).

No.

Characters with their coded states

1. Chromosome number $(2 n)$

$$
(0)=20(1)=22
$$

2. Pseudostem height $(\mathrm{m})$

$$
(0)=\leq 2(1)=>2
$$

3. Pseudostem color

$$
(0)=\text { Green }(1)=\text { Green yellow }(2)=\text { Purple brown }
$$

4. Sheath blotches

$$
(0)=\text { Black }(1)=\text { Brown }
$$

5. Petiole canal $(0)=$ Wide with erect margins $(1)=$ Margins curved inward $(2)=$ Straight with erect margins

6. Pctiole

$$
(0)=\text { waxy }(1)=\text { nonwaxy }
$$

7. Leaves

$$
(0)=\operatorname{waxy}(1)=\text { nonwaxy }
$$

8. Insertion point of leaf blade

$$
(0)=\text { Symmetric }(1)=\text { Asymmetric }
$$

9. Shape of leaf blade base $(0)=$ Both sides rounded $(1)=$ One side rounded and one pointed $(2)=$ Both sides pointed

10. Peduncle hairiness

$(0)=$ Hairless $(1)=$ Slightly hairy $(2)$ = Very hairy

11. Bunch posture

$$
(0)=\text { Horizontal }(1)=\text { Erect }(2)=\text { Hanging at angle of } 45^{\circ}
$$

12. Bunch appearance

$$
(0)=\operatorname{Lax}(1)=\text { Compact }(2)=\text { Very Compact }
$$

13. Rachis Position

$(0)=$ Horizontal $(1)=$ Erect $(2)=$ Falling vertically

14. Rachis Type

$(0)=$ Present and male bud persistent $(1)=$ Present and male bud degenerated

15. Male bud type

$(0)=$ Normal $(1)=$ Degenerated before maturity

16. Male bud shape

$(0)=$ Like a top $(1)=$ Ovoid $(2)=$ Lanceolate

17. Male bud size $(\mathrm{cm})$

$$
(0)=20 \mathrm{~cm}(1)=21 \text { to } 30 \mathrm{~cm}(2)=>30 \mathrm{~cm}
$$

18. Bract base shape

$$
(0)=\text { Small shoulder }(1)=\text { Medium }(2)=\text { Large shoulder }
$$


Marphological characterization of Malaysian wild banana - Muhammad Asif Javed et al.

Table 2. Continued

\begin{tabular}{ll}
\hline \hline No. $\quad$ Characters with their coded states \\
\hline
\end{tabular}

19. Bract apex shape
$(0)=$ Slightly pointed $(1)=$ Intermediate $(2)=$ Obtuse $(3)=$ Obtuse and split

20. Bract imbrication

$(0)=$ Old bracts overlap at apex of the bud $(1)=$ Young bracts slightly overlap $(2)=$ Young bracts greatly overlap

21. Color of bract external face

$(0)=$ Purple to red $(1)=$ Purple brown to violet $(2)=$ Pink purple to green yellow

22. Color of the bract internal face

$(0)=$ Purple yellow to creamy $(1)=$ Yellowish red to light violet $(2)=$ Green yellow to purple brown

23. Color on the bract apex

$(0)=$ Without discolored lines $(1)=$ With discolored lines

24. Color stripes on bract

$(0)=$ Without discolored lines $(1)=$ With discolored lines

25. Fading of color on bract apex

$(0)=$ Color homogeneous $(1)=$ Color discontinuous

26. Male bract shape

$(0)=\mathrm{X} / \mathrm{Y}<0.28($ Lanceolate) $(1)=0.28<\mathrm{X} / \mathrm{Y} \leq 0.30$ (medium) $(2)=\mathrm{X} / \mathrm{Y}>0.30$ (ovoid)

27. Male bract lifting
$(0)=$ Lifting one at a time $(1)=$ Lifting two or more at a time

28. Bract behavior before falling

$(0)=$ Revolute (rolling) $(1)=$ Non-revolute $($ not rolling)

29. Male flower behavior

$(0)=$ Falling before bract $(1)=$ Falling after bract

30. Compound tepal basic color

$(0)=$ Creamy $(1)=$ Yellow

31. Lobe color of compound tepal

(0) = Creamy (1) = Yellow (2) = Green

32. Free tepal apex development

(0) = Developed $(1)=$ Little or no development

33. Style shape

$(0)=$ Straight $(1)=$ Curved under stigma $(2)=$ Curved at the base

34. Fruit shape

$(0)=$ Straight in the distal part $(1)=$ Straight or slightly curved $(2)=$ Curved

35. Transverse section of the fruit
$(0)=$ Rounded $(1)=$ Slightly ridged $(2)=$ Pronounced ridged

36. Fruit apex

$(0)=$ Bottle necked $(1)=$ Blunt ridges

37. Remains of flower relicts

$(0)=$ Persistent style $(1)=$ Without persistent flower relicts 
Table 2. Continued

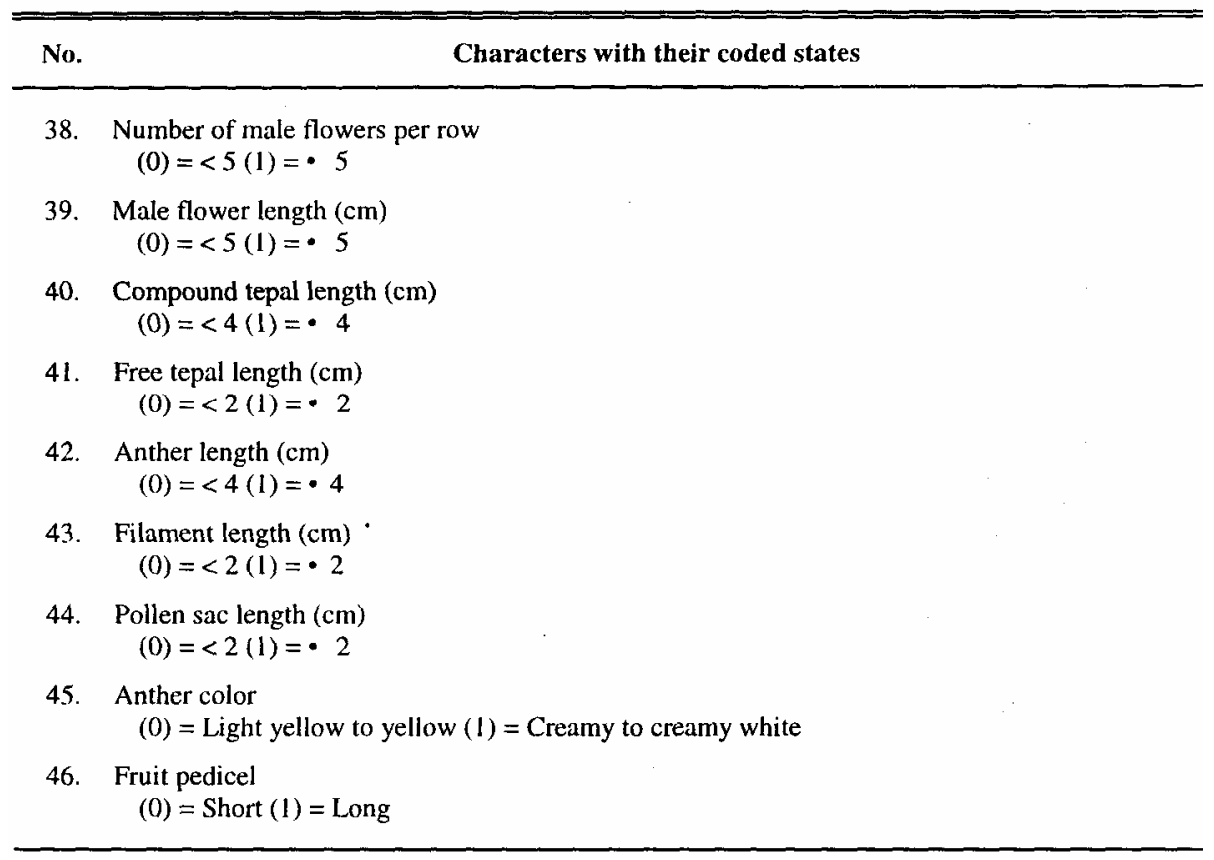

Principal Component Analysis was conducted as it has the advantage of abstracting factors, one of which may represent some underlying variables like overall size, which may affect many characters. There were several significant factors but only the first four were extracted. Factor scores were calculated for each OTU and the first two plotted in a scatter diagram.

\section{RESULTS}

A single linkage cluster method grouped $M$. acuminata samples into four where BC2 (Musa violascens) and Gala (Musa balbisiana) were clearly separated (Fig. 2). The highland banana was clearly differentiated from lowland banana forms based on deep purple brown color of the pseudostem, petioles, and male bracts, a non-waxy petiole and lamina with both sides of lamina bases rounded and creamy colored internal bract face. The lowland populations were found to be overlapping irrespective of their geographical origin and no distinct separation was observed.

Flava and Segun were collected from central region of peninsular Malaysia while Sintok and J-4 found in the northern region were grouped together and showed large morphological similarities. BD1, BD2, RI and IPTJ populations were from 
southwest of the peninsula, while BC1, Kra and PPC were from the central region (Fig. 1). These accessions were morphologically similar possibly reflecting the overlapping of the geographical ranges in the central lowland regions. Geographically, Rangis and Perak were of very diverse origin but showed high morphological similarity, differing only in bract imbrication. Rangis is characterized by young bracts greatly overlapping compared to the convolute male bud observed in Perak. The last group comprised Gala and BC2. These were well separated from $M$. acuminata with little or no similarity.

The position of all Musa accessions on the first and second principal components as derived from the original pairwise correlations among the accessions are shown in Figure 3. The first factor accounted for 36.73\% variation while the second factor showed only $11.14 \%$ variation. A significant percentage decrease was observed with components three (10.36\%) and four (8.79\%).

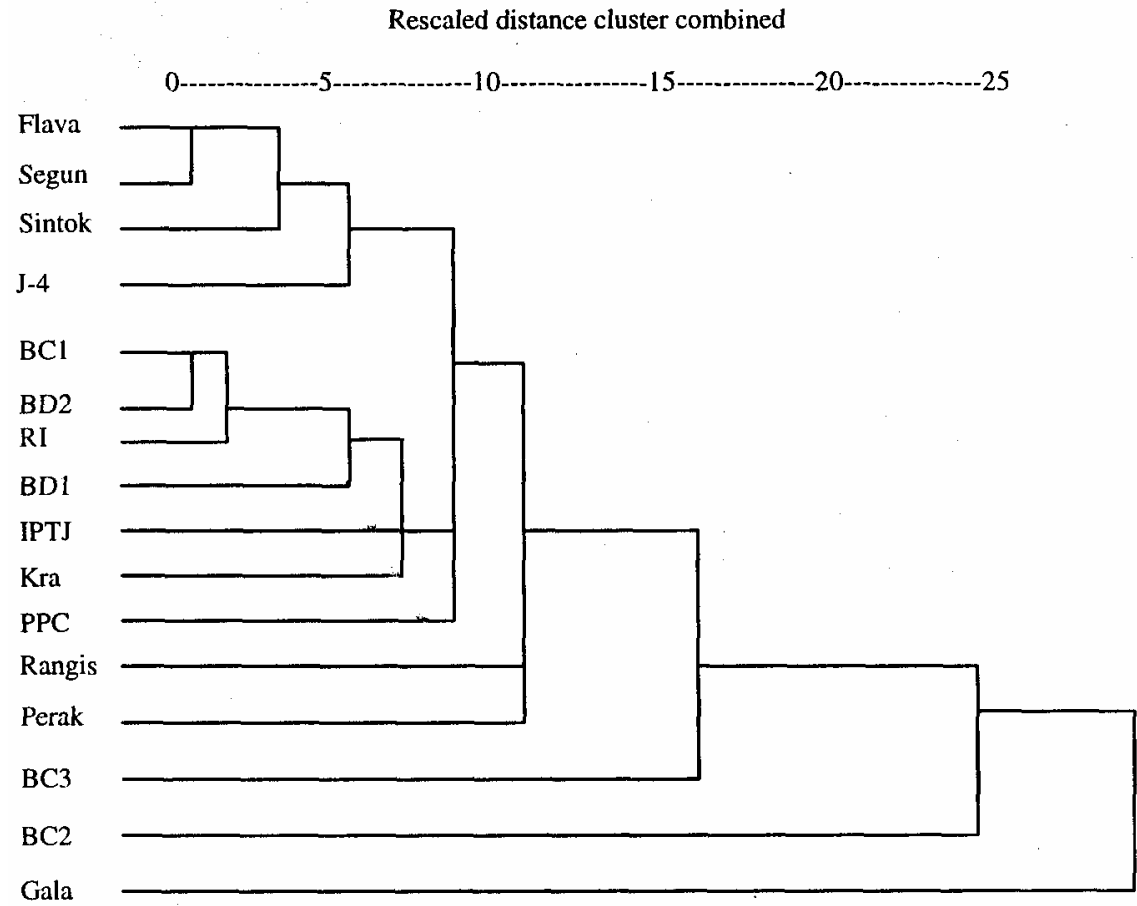

Fig 2. Phenogram of 16 Musa accessions based on morphological characters and chromosome number. Musa acuminata accessions were separated into four groups based on Single Linkage and Squared Euclidean Distance. The highland banana BC3 was well separated at the bottom from lowland accessions. The two species BC2 and Gala were also clearly separated from the Musa acuminata. 


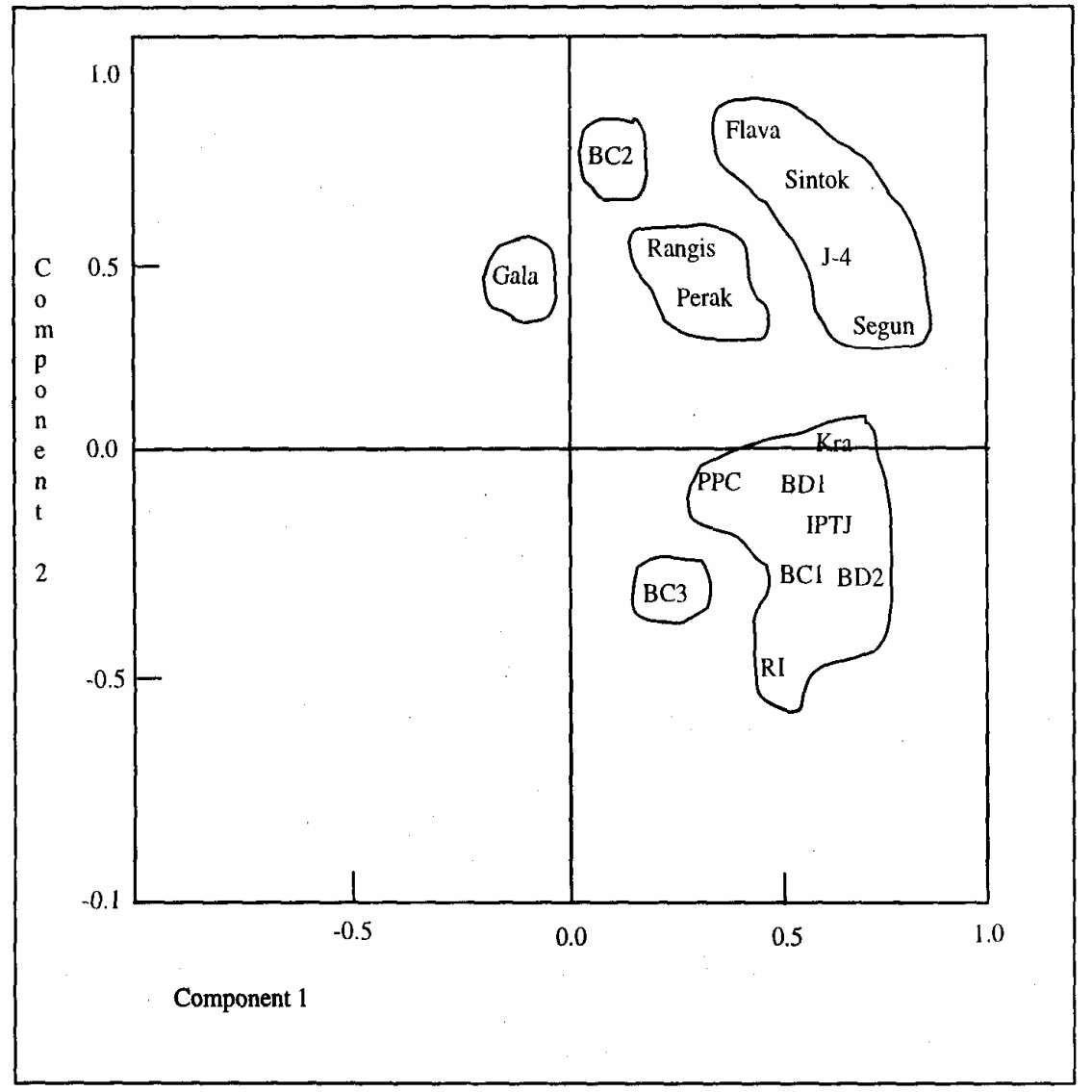

Fig 3. Principal component analysis. PCA showing relative positions on the first and second principal components of 16 accessions of MUM species based on 46 morphological characters and chromosome number. Musa acuminata samples showed large morphological variation and grouping of the different accessions was in agreement with that of cluster analysis.

Component one clearly separated the samples PPC and BC3, the highland banana, from rest of the accessions of $M$. acuminata, whereas second component separated Kra. The major groupings observed were BD1, IPTJ, BC1, BD2 and RI, a second group composed of Segun, J-4, Sintok, and Flava, and finally Rangis and Perak (Fig. 3).

Table 4 shows that of the 46 characters used in the analysis 13 had loadings of more than 0.5 on the first component. Four of these characters i.e. chromosome number, bract apex shape, male bract lifting and fruit apex were found to be useful 
in separating the three species samples M. acuminata, M. balbisiana (Gala) and $M$. violascens (BC2), respectively. Five characters could differentiate both interspecific and intraspecific accessions were bunch posture, bunch appearance, bract base shape, bract imbrication and transverse section of fruit. M. acuminata accessions could be differentiated based on these four characters e.g. rachis type, bract behaviour before falling, male flower behaviour before falling and remains of floral relicts .

Table 3. Fruit bunch (five bunches/sample) characteristics of different wild Musa acuminata bananas

\begin{tabular}{lclccc}
\hline Sample & $\begin{array}{c}\text { Bunch weight } \\
(\mathbf{k g})\end{array}$ & No. of hands & $\begin{array}{c}\text { No. of fingers/ } \\
\text { hand }\end{array}$ & $\begin{array}{c}\text { Finger length } \\
(\mathbf{c m})\end{array}$ & $\begin{array}{c}\text { Finger diameter } \\
\text { (cm) }\end{array}$ \\
\hline RI & $2.94 \pm 0.10$ & $5.4 \pm 0.25$ & $22.8 \pm 0.50$ & $14.94 \pm 0.2$ & $1.52 \pm 0.04$ \\
IPTJ & $1.96 \pm 0.02$ & $.5 .2 \pm 0.20$ & $15.4 \pm 0.40$ & $7.98 \pm 0.05$ & $1.48 \pm 0.04$ \\
BD1 & $1.98 \pm 0.02$ & $5.8 \pm 0.20$ & $14.4 \pm 0.60$ & $9.60 \pm 0.20$ & $1.82 \pm 0.02$ \\
BD2 & $7.94 \pm 0.04$ & $9.8 \pm 0.20$ & $12.8 \pm 0.50$ & $9.80 \pm 0.40$ & $2.0 \pm 0.03$ \\
BCl & $9.86 \pm 0.10$ & $10.0 \pm 0.3$ & $21.0 \pm 0.50$ & $14.0 \pm 0.32$ & $1.84 \pm 0.02$ \\
BC3 & $5.1 \pm 0.11$ & $10.0 \pm 0.4$ & $17.4 \pm 0.70$ & $14.90 \pm 0.04$ & $1.96 \pm 0.02$ \\
Kra & $4.02 \pm 0.05$ & $4.9 \pm 0.08$ & $14.0 \pm 0.30$ & $9.0 \pm 0.45$ & $1.5 \pm 0.03$ \\
Flava & $3.98 \pm 0.07$ & $4.90 \pm 0.3$ & $19.4 \pm 0.40$ & $9.20 \pm 0.40$ & $1.5 \pm 0.07$ \\
Perak & $3.96 \pm 0.07$ & $5.20 \pm 0.2$ & $16.0 \pm 0.30$ & $9.80 \pm 0.09$ & $1.6 \pm 0.03$ \\
Rangis & $2.3 \pm 0.20$ & $7.20 \pm 0.4$ & $19.4 \pm 0.30$ & $8.20 \pm 0.40$ & $1.5 \pm 0.04$ \\
Segun & $2.2 \pm 0.12$ & $5.4 \pm 0.20$ & $14.0 \pm 0.30$ & $7.80 \pm 0.40$ & $1.72 \pm 0.05$ \\
Sintok & $3.94 \pm 0.04$ & $7.8 \pm 0.20$ & $17.6 \pm 0.30$ & $8.60 \pm 0.40$ & $1.52 \pm 0.04$ \\
J-4 & $1.98 \pm 0.07$ & $7.20 \pm 0.2$ & $19.8 \pm 0.20$ & $6.92 \pm 0.04$ & $1.44 \pm 0.03$ \\
PPC & $3.96 \pm 0.07$ & $7.4 \pm 0.30$ & $17.6 \pm 0.80$ & $9.80 \pm 0.12$ & $3.5 \pm 0.03$ \\
\hline
\end{tabular}

Eight characters which accounted for much of the variation were contributed by the second component. The characters like leaf and petiole waxyness, insertion point of leaf blade clearly separated the highland form BC3 from the lowland form of $M$. acuminata accessions.

Six characters contributed largely on component three which separated the RI accession based on male bud degeneration at maturity and yellow color of compound tepal while Kra and PPC were separated based on the rachis position and free tepal development. The fourth component showed four characters with loadings of more than 0.5. Pseudostem color had the highest loading compared to the other three characters and clearly separated the highland banana BC3 from the other accessions. The grouping of accessions in PCA corresponded well to that of cluster analysis. 
Table 4. Characters found most variable based on first four principal components. Thirty characters with loadings of more than 0.5 (in bold) on components one, two three and four separating different accessions and groups of accessions of Musa samples in PCA.

\begin{tabular}{|c|c|c|c|c|}
\hline Characters & PCI & PC2 & PC3 & PC4 \\
\hline Chromosome number & -0.529 & -0.633 & 0.171 & -0.005 \\
\hline Pseudostem height & -0.002 & 0.005 & 0.622 & 0.114 \\
\hline Pseudostem color & -0.136 & 0.369 & 0.115 & -0.708 \\
\hline Leaves waxy & 0.325 & 0.757 & -0.110 & -0.261 \\
\hline Petioles waxy & 0.325 & 0.757 & -0.110 & -0.261 \\
\hline Petiole canal & 0.175 & -0.002 & -0.851 & 0.06 \\
\hline Insertion point of leaf blade & -0.303 & 0.543 & 0.100 & -0.09 \\
\hline Bunch posture & 0.723 & -0.05 & 0.456 & -0.216 \\
\hline Bunch appearance & 0.608 & 0.164 & 0.569 & 0.09 \\
\hline Rachis position & -0.315 & 0.171 & 0.550 & 0.378 \\
\hline Rachis type & 0.581 & -0.115 & 0.506 & -0.292 \\
\hline Male bud type & -0.315 & 0.171 & 0.550 & 0.378 \\
\hline Bract base shape & -0.502 & 0.300 & -0.373 & 0.376 \\
\hline Bract apex shape & 0.851 & -0.309 & 0.182 & -0.07 \\
\hline Bract imbrication & 0.786 & -0.08 & -0.262 & 0.222 \\
\hline Color on bract apex & 0.005 & 0.383 & -0.104 & -0.666 \\
\hline Color stripes on bract & -0.221 & 0.302 & -0.227 & 0.666 \\
\hline Male bract lifting & 0.923 & 0.262 & 0.06 & 0.009 \\
\hline Bract behavior before falling & 0.923 & 0.262 & 0.06 & 0.09 \\
\hline Male flower behavior & -0.613 & -0.164 & 0.216 & -0.562 \\
\hline Compound tepal basic color & -0.315 & 0.171 & 0.550 & 0.378 \\
\hline Lobe color of compound tepal & 0.07 & -0.787 & 0.09 & 0.04 \\
\hline Free tepal apex developed & -0.423 & 0.313 & -0.564 & 0.310 \\
\hline Fruit shape & -0.190 & 0.519 & 0.209 & 0.001 \\
\hline Transverse section of the fruit & 0.563 & 0.408 & -0.246 & 0.392 \\
\hline Fruit apex & 0.748 & 0.176 & -0.02 & 0.331 \\
\hline Remains of male floral relicts & -0.765 & -0.141 & -0.07 & 0.109 \\
\hline Number of male flowers per row & -0.305 & -0.713 & 0.208 & -0.211 \\
\hline Male flower length & 0.204 & -0.454 & 0.087 & 0.506 \\
\hline Filament length & 0.219 & -0.724 & -0.210 & -0.106 \\
\hline
\end{tabular}

The majority of samples from the central region, BC3, BC1, BD2, RI and Kra tended to be tall. Perak, Rangis, PPC, Sintok, J4, and Segun were semi-dwarf with plant heights of less than $2 \mathrm{~m}$. Deep purple brown color of pseudostem and petioles were found useful to differentiate highland banana form (BC3). Characteristically, 
highland banana showed non-waxy leaves and petioles compared to waxy types in all M. acuminata samples. Generally, the leaf sheath in wild bananas is narrow on both sides forming the petiole, which is rounded beneath and channeled above, retaining the crescent shaped section of the sheath. Petiole canal of Perak, PPC and RI was observed to have wide and erect petiole margins compared to curve or straight erect margins in other samples. Sample BC3 had both sides of the lamina pointed, whereas J-4 showed one side rounded and the other side pointed while other samples had round lamina bases.

Samples BCI, BD1, BD2, RI, IPTJ and BC3 (a highland banana) were characterized with very hairy fruit peduncles. The Perak, Sintok, J-4 and Segun samples have hairless fruit peduncles with the exception of Rangis, PPC and Flava having slightly hairy peduncles. PPC had a very compact fruit bunch compared to compact or lax fruit bunches in other samples. Rachis position was also found to be a useful character to differentiate both Kra and PPC, which had rachis falling vertically, compared to the normal horizontal position. Fruits were biseriate; rachis and male bud were persistent in all accessions until the fruit maturity except the sample RI where male bud was degenerated before fruit maturity. Fruit shape was straight in Kra or slightly curved or curved in all other samples. Observations made on fruit transverse section showed that sample PPC had a rounded transverse section, while IPTJ showed pronounced ridges.

All samples studied showed a normal male bud (male bud and rachis persisted till fruit maturity) with the exception of RI where the male bud degenerated before fruit maturity. Perak, BC3, BCI, PPC and Flava are characterized with medium size of bract. A strong imbrication, with young bracts overlapping at the apex of the male bud was observed in Rangis, whereas Flava and Segun showed slight bract imbrication. Other samples of $M$. acuminata showed convolute bract behavior. The highland banana BC3 could be differentiated from other forms with a distinct deep purple brown external and creamy color of internal bract face. Similarly, Flava, a yellow bracted mutant of M. acuminata, added more complexity to bract color characterization. Bract curling was also found to be useful for differentiating $M$. acuminata accessions from $M$. balbisiana.

All samples had basal flowers which were functionally female and contain stamens reduced to staminoids, whereas distal flowers had functionally male flowers and were female infertile. The male flowers fell off before bract dispersal in Rangis, BD1 and IPTJ. Compound tepal basic color was observed to be creamy except the sample RI (yellow). Free tepal development was observed for samples Kra and PPC, whereas all other samples had little or no development. Number of male flowers per row ranged from 5 to 11. Sample IPTJ had the minimum number of male flowers per row. The length of the male flowers ranged from $3 \mathrm{~cm}$ in the case of IPTJ and $7 \mathrm{~cm}$ for Sintok. The maximum filament length was observed in the sample BCI $(4.4 \mathrm{~cm})$ and the minimum of $1.1 \mathrm{~cm}$ in BC3. 
As agronomic characters are greatly affected by the environment, they are not useful for classification purposes but are of great importance for breeding new cultivars. The agronomic characters recorded were bunch weight, number of hands per bunch, number of fingers per hand, finger length and finger diameter.

Fruit bunch weight ranged from $1.96 \pm 0.02$ to $9.86 \pm 0.10 \mathrm{~kg}$. Large fruit bunches were observed in samples BC1, BD2, BC3, Kra and PPC, respectively (Table 3). Samples with relative large fruit hands were observed in BC3, BC1, and BD2. For fingers per hand, the maximum fruits were produced by RI $(22.8+0.5)$ compared to a minimum of $12.8 \pm 0.5$ in BD2. Large finger length was observed in the samples RI $(14.94 \pm 0.2 \mathrm{~cm}), \mathrm{BC} 3(14.90+0.04 \mathrm{~cm})$, and BC1 $(14.0 \pm 0.32 \mathrm{~cm})$. Finger diameter ranged from $1.44+0.03$ to $3.5 \pm 0.03 \mathrm{~cm}$ where large finger diameters were observed in PPC followed by BD2 and BC3, respectively.

M. acuminata fruit bunches were found to contain a large number of seeds ranging 30-120 per fruit. Seeds range between 5-6 mm in diameter and irregularly subglobose in shape. Seeds were grayish-brown in color. Germination studies in sand beds resulted into 1-2\% germination. However, in vitro embryo culture resulted into more than $90 \%$ seed germination (Asif et al. 2001a). IPTJ produced albino seedlings when cultured in vitro.

\section{DISCUSSIONS}

Morphological characters used for wild banana characterization are taxonomic and not agronomic. Harlan (1975) argued that it will be breeders who will make use of the classifications of crop germplasm and they will be mainly concerned with the genetic compatibility, while morphological characters will be secondary. However, Engels (1986) stated that the importance of a germplasm collection to a breeding program is strongly dependent on the availability of accurate descriptions of the accessions and on the taxonomic identification of the germplasm. In this study, 10 quantitative characters were used and only four were found useful, according to PCA (Table 4).

In general, most of the north Malaysian accessions were semi-dwarf. However, this character is not useful for classification because of variation due to environmental factors. Moreover, for breeding purposes, it appears that plants with semidwarf pseudostem height are preferred and capable of withstanding both stress conditions and fruit bunch weight at maturity without propping. Similarly, there is less loss from wind damage, harvesting is easier and broadly, they imply high yields and easy care at a little extra expense for planting material (Simmonds 1986).

The number of male flowers per row was found to be varying within the same male bud similarly, flowers and style length could be modified by environmental factors. Hence, these characters are not useful for characterization (Ortiz \& Sevilla 
1997). Quantitative characters might not be appropriate for such task in Musa, because all were significantly affected by genotype environmental interactions.

Pseudostem and petiole sheath color was observed to be useful (Simmonds 1955) in the identification of the highland form BC3 from the other two groups. The sheath color is the result of environment or due to genetic factors, could not be further differentiated, as the highland form did not survive under lowland conditions. Lamina bases are also found to be interesting characters. Skutch (1930) reported that the meristem of one lamina half frequently extends further down the petiole than the other. There is no rule as to which side is produced furthest basally. In cases of smaller size of the lamina, the inequality is much less conspicuous. The basal inequality of the lamina halves is a lasting testimony that they are of independent origins. Very late appearance of the lamina halves, compared with the other portion of the leaf, also points to a phylogenetically later origin.

A large amount of variability was observed in the fruit shape of different Musa acuminata accessions. However, it was observed to be variable even within the same fruit bunch and thus, did not seem to be a reliable character. Persistent style and staminodes were observed only in the Perak. However, this character could be related to slow maturity. Karamura (1999) stated that clones growing at high altitudes usually have non-persistent styles and stamens, which may take a long time to drop.

Rachis position could be used to differentiate Kra and PPC from other accessions. The absence of the rachis and male bud observed in RI was considered a mutation (De Langhe 1961). Bract imbrication was regarded as an interesting character both at interspecific and intraspecific levels. Bract imbrication was used by Simmonds (1955) mainly to differentiate 'Kedah form' (ssp. siamea) from the Selangor and Cameron forms. In the present study three samples, Rangis, Flava and Segun, were observed with imbrication. Rangis showed greater imbrication compared to the other two samples. In this study, three samples, Sintok, J-4 and Rangis, were collected from Kedah and Kelantan, respectively. Whereas the samples Flava and Segun with slight imbricated bracts were collected from Pahang states, the center of diversity of 'Selangor form' (Simmonds 1955). Bract imbrication was found to vary within the accessions of 'Kedah form' even within the ^ame geographical range. Hari (1968) also recommended that bract imbrication should be rejected as taxonomic character in the classification of Musa acuminata accessions subject to morphological changes during bud development. The data confirmed that bract imbrication could not be used as a reliable character for classification.

PPC was differentiated by having a very compact fruit bunch hanging at an angle. It was observed that accessions having a pendulous rachis had compact fruit bunches. Similar observations were made by De Langhe (1961) where he found a pendulous bunch which commonly has fruits requiring towards the peduncle or rachis. However, Karamura (1999) observed clones that showed no geotropic reaction, had pendulous bunches. A sub-horizontal bunch posture (angle of female 
axis) is under the control of additive gene action of dominant alleles with threshold effect (Ortiz 1993). This character is of economic importance as pendulous bunch is the most symmetrical and is therefore better adapted to transportation.

Great variability also accounted for bract color, both at interspecific and intraspecific levels. However, the situation was more complex at intraspecific level where different samples of $M$. acuminata had different bract colors. Highland banana sample BC3 (ssp. truncatd) was classified based on the bract color. Bract color characterization based on anthocyanin analysis using high performance liquid" chromatography (HPLC) showed very distinct anthocyanin pattern in highland banana compared to similar anthocyanin composition observed in lowland populations (Asif et al. $200 \mathrm{Ib}$ ). Flava, a yellow bracted mutant, showed the absence of anthocyanin (Simmonds 1955).

During the current study, several of the observed abnormalities included the transformation of the free tepals and the different number of male flowers in alternate rows. Different number of male flower rows were also varied in the same male bud of the sample BD2. In the case of Sintok, two male flowers were fused together and had a total of 11 anthers instead of 10 (5 each). Similarly, sample RI showed fusing of the fruits and degeneration of male bud and rachis. Nair and Karunakaran (1962) and Jacob (1952) have reported similar abnormalities in cultivated bananas.

Cluster analysis grouped all $M$. acuminata accessions into four groups where north Malaysian accessions were closely related with Selangor group and highland banana sample was well separated. PCA produced similar grouping of the acces${ }_{t}$ sions and also showed that they were phonetically related. It thus gave a more accurate representation of how similar accessions were phenetically related to each other, although the overall picture was very similar to that of cluster analysis.

The first group contained accessions Flava, Segun, Sintok and J-4. They were collected from different geographical regions but showed large morphological similarities. Most of the characters were observed to overlap with other lowland $M$. acuminata accessions (groups 2 \& 3). This was similarly observed in the case of Rangis and Perak, which were collected from Kelantan and Perak. Rangis, a typical Kedah form (ssp. siamea), showed similarities with Perak, a sample collected from Perak (from geographical range of ssp. malaccensis). These characters were variable developmentally (Hari 1968; Karamura 1999).

The second group comprised a large number of accessions mainly collected from the ssp. malaccensis range. They shared many morphological characters and were, as expected, closely clustered together. Free tepal development and rachis position could be an interesting character for the identification of PPC and Kra. The highland banana accession (BC3) growing at an altitude of $2000 \mathrm{~m}$ was clearly separated from the lowland accessions and showed great ecological and morphological variability from the lowland accessions. This accession was also found to be 
different in growth habit, anthocyanin composition (Asif et al. $200 \mathrm{Ib}$ ) and genomic DNA content (Asif et al. 2001c) compared to lowland forms.

It was suggested that the highland banana form ssp. truncata (Simmonds 1955), could be separately classified based on morphology since the large morphological variability observed among lowland accessions made it difficult to group them into other distinctive groups. Most of these accessions had overlapping morphological characteristics irrespective of their geographical relationship.

The variation observed among different forms of Musa acuminata could be related to their partial geographical isolation (highlands and lowlands) and changes in gene frequencies due to the small wild banana population sizes resulting from genetic drift and hybridization of different subspecific forms. Mutations could also be an important factor contributing to the total variability.

Different subspecific forms of Musa acuminata had been reported to cross frequently within the same geographical range. It had been repeatedly demonstrated that hybridization between species and subspecies belonging to the same section or between species in different sections occur readily in Musa. Some of these hybrids are fertile. Two well-known examples include the $M$. balbisiana and $M$. textilis interspecific hybrids referred to as "Canton" cultivar; and the other is $M$. textilis and $M$. balbisiana hybrid known as "Pacol" (Tezenas du Montcel 1987). The observations based on cytological and field experiments (e.g. Dodds \& Simmonds 1948) showed that several forms are interfertile, thus the whole assemblage formed a 'panmictic unit' (so far as geography permits). Simmonds (1955) further suggested that field evidence of hybridity was most striking where populations of the ssp. malaccensis and ssp. truncata occur together. Furthermore, the occurrence of mutations further increased the range of morphological variability among the populations (Gonzales de Leon \& Faure 1992).

The fourteen $M$. acuminata populations studied consisted of a small number of individuals. Small populations may not be stable because of dispersive processes which lead to the division of the populations into groups or sub-populations as observed in the case of wild bananas, where different populations observed in the same area appeared variable. Secondly, it reduces the genetic variability and increases homozygosity. Since in sub-populations mating between similar individuals takes place (i.e. inbreeding), genetic variability decreases within the groups, some genes are fixed and some eliminated, thus increasing homozygosity (Wright 1951). This was observed in most of the wild banana populations where little variation was observed within the populations compared to among the populations and the variation observed was likely due to mutations appearing as a result of inbreeding. The development of different local populations of open pollinated plants is an example of the dispersive processes at work in natural populations. Brieger (1950) found a number of local populations of maize in South America where populations were quite distinguishable among themselves but each population was highly uniform. 
M. acuminata produced a large amount of seeds as a result of open pollination. Majority of the seeds observed had normal embryos, whereas few abnormal seeds showed the absence of embryo/endosperm or both. More than $90 \%$ embryos were germinated, thus could enable to study a large number of hybrid populations for banana breeding. Bananas are cross pollinated species and it will be interesting to know the effect of inbreeding on seed bearing and germination.

Morphological characters studied although found useful at interspecific level was less so at intraspecific level. There were only a few morphological characters found to be useful to differentiate highland banana population from lowland, whereas there was no distinct pattern observed within lowland banana populations. Therefore, it seems important that more sensitive markers be used to characterize these populations. Genomic DNA markers may offer the useful systems to increase our knowledge about wild banana diversity.

\section{ACKNOWLEDGMENTS}

The authors are grateful to the Ministry of Science and Technology Malaysia for financial support. Thanks are also due to Dr Siti Hawa Jamaluddin, Malaysian Agriculture Research Development Institute (MARDI) for the supply of materials.

\section{REFERENCES}

Asif, M. J., Mak, C. and R. Y. Othman 2001a. In vitro zygotic embryo culture of a wild Musa acuminata ssp. malaccensis and factors affecting the germination and seedling growth. Plant Cell, Tissue and Organ Culture 67 (3): 267-270.

Asif, M. J., C. Mak, and R. Y. Othman. 2001b. Characterization Of Malaysian wild Bananas based on anthocyanins. BIOTROPIA 16:28-38

Asif, M. J., C. Mak, and R. Y. Othman. 2001c. Characterization of indigenous Musa species based on Flow Cytometric Analysis of Ploidy and Nuclear DNA content. Caryologia 54 (2): 161 -168.

Brieger, F. J. 1950. The genetic basis of heterosis in maize. Genetics, 35(4).

Buddenhagen, I.W., 1990. Banana breeding and Fusarium wilt. In: Fusarium Wilt of Banana (Ploetz, R.C. ed.). St. Paul, MN, USA: APS Press/Amer. Phytopathology Soc., p.: 107-113.

Cheesman, E. E. 1947. The classification of Bananas. Kew Bull., 2:97-117.

Dodds, K. S. and N. W. Simmonds. 1948. Sterility and parthenocarpy in diploid hybrids of Musa. Heredity, 2: 101-117.

De Langhe, E. 1961. La taxonomie du bananier plantain en Afrique equatoriale. J. Agric.Trop. Bot. Appl., 8:417-449.

Engels, J. M. M. 1986. The identification of Cacao cultivars. Acta Horticulturae, 182: 195-202.

FAO., 1999. FAO 1999 Yearbook, Food and Agriculture Organization. Rome. 
Morphological characterization of Malaysian wild banana - Muhammad Asif Javed et al.

Hari, P. C. 1968. Bract imbrication as a taxonomic character in Musa acuminata. Trop. Agri. Trinidad, Vol. 45, No. 2:99-108.

Harlan, J. R. 1975. Crops and man. American Society of Agronomy and Crop Science Society of America, Madison, Wisconson.

IBPGR. 1996. Descriptors for banana (Musa spp.). IBPGR, Rome.

Gonzales De Leon, D. and S. Faure. 1992. Genetic Mapping of the Banana Diploid Genome: toward an integrated approach to the study of the Musa genome and the use of molecular marker technologies in Musa breeding. In: Proceeding of the Workshop on Biotechnology Applications for Banana and Plantain Improvement. San Jose, Costa Rica. p. 29-51.

Jacob, K. C. 1952. Madras Bananas, a monograph. Madras.

Karamura, D. A. 1999. Numerical taxonomic studies of the East African Highland Banana (Mum AAA East Africa) in Uganda. Ph.D. thesis, Department of Agricultural Botany, University of Reading, January 1998. INIBAP. Montpellier, France.

Kiew, R. 1987. Notes on the natural history of the Johor Banana, Musa gracilis Holtum. Malayan Nature Journal, 41:239-248.

Nair, N. R. and K. Karunakaran. 1962. A note on the occurrence of staminoidy of petal in Musa. Indian. J. Hort., 19(3\&4): 176-177.

Norusis. M.J. 1985. SPSS, Advanced Statistics Guide. New York: McGraw Hill.

Ortiz, R. 1993. Ploidy manipulations for genetic analysis and improvement of plantain and banana (Musa spp.). In: Chromosome Manipulations of Higher Plants (Peloquin, S. J. and E. T. Bingham. Ed.). Madison, USA, University of Wisconsin.

Ortiz, R. and R. Sevilla. 1997. Quantitative descriptors for classification and characterization of highland Peruvian maize. Plant Genetic Resour. Newslett., 110: 49-52.

Purseglove, J. W. 1972. Tropical Crops. Monocotyledons. Longman, London.

Shepherd, K. 1988. Observations on Musa taxonomy. In: Identification of genetic diversity in the genus Musa. Proceedings of an International workshop held at Los Banos, Philippines (Jarret, R. L. ed.), 510 September 1988. p 158-165

Shepherd, K. 1999. Cytogenetics of the Genus Musa. International Network for the Improvement of Banana and Plantains, Montpellier, France, p: 135-140.

Simmonds, N. W. 1955. Wild bananas in Malaya. Malayan Nature Journal, 10: 1-8.

Simmonds, N. W. 1962. The Evolution of the Bananas. London, UK: Longman.

Simmonds, N. W. 1986. Classification and breeding of bananas. In: Banana and plantains breeding strategies. (Persley, G. J. and E. A. De Langhe ed.). Proceedings of an International workshop held at Cairns, Australia, 13-17 October, 1986.

Skutch, A. F. 1930. On the development and morphology of the leaf of the banana. (Musa sapientum L.). Amer. J. Bot, 17:252-71.

Tezenas du Montcel, H. 1987. Plantain Bananas. CTA. Paris and MacMillan. London.

Vakili, N. G. 1965. Fusarial wilt resistance in seedlings and mature plants of Musa species. Phytopathology, 55: 135-140.

Wright, S. 1951. The genetic structure of populations. Ann. Eugenetics, 15: 323-354. 